\title{
Metal Coordination and Aggregation Properties of Chiral Polythiophenes and Polythienylethynylenes ${ }^{\mathrm{a}}$
}

\author{
James R. Matthews, Francesca Goldoni, Huub Kooijman, \\ Anthony L. Spek, Albertus P. H. J. Schenning, * E. W. Meijer*
}

A series of chiral thio- and oxo-substituted polythiophenes and polythienylethynylenes has been synthesised and investigated. The replacement of an oxo-linkage by a thio-linkage distorts and/or inhibits the helical aggregation behaviour. The quenching of fluorescence upon coordination to palladium is also radically different depending on the presence of oxo- or thio-substitution of the thiophene units. The alkylthio-substituted polythiophenes and polythienylethynylenes do act as sensors for palladium by quenching of their fluorescence to a significantly greater extent than the quenching observed for nonthio functionalised polythiophenes and polythienylethynylenes.
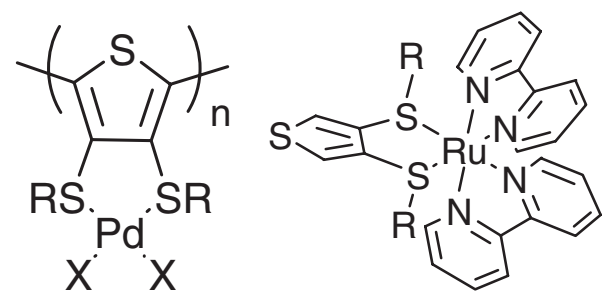

\section{Introduction}

$\pi$-Conjugated polymers ${ }^{[1-3]}$ have applications as potential sensors $^{[4]}$ for biological, ${ }^{[5,6]}$ organic ${ }^{[7,8]}$ and inorganic ${ }^{[9-11]}$ materials and in most of the cases rely on the photophysical properties of $\pi$-conjugated polymers changing in a reliable and reproducible way on exposure to analytes. Aggregation may have a strong influence on the sensing abilities of materials. ${ }^{[4]}$ Aggregated structures may show

J. R. Matthews, F. Goldoni, A. P. H. J. Schenning, E. W. Meijer Macromolecular and Organic Chemistry, Eindhoven University of Technology, P. O. Box 513, 5600 MB, Eindhoven, The Netherlands E-mail: a.p.h.j.schenning@tue.nl; e.w.meijer@tue.nl

H. Kooijman, A. L. Spek

Bijvoet Center for Biomolecular Research, Crystal and Structural Chemistry, Utrecht University, Padualaan 8, $3584 \mathrm{CH}$, Utrecht, The Netherlands

$\mathrm{a}$ 品 Supporting information for this article is available at the bottom of the article's abstract page, which can be accessed from the journal's homepage at http://www.mrc-journal.de, or from the author. the ability to more effectively signal the presence of analytes through greater changes in spectroscopic properties on encountering analyte species ${ }^{[12]}$ and/or enhanced abilities to interact with desired analytes. ${ }^{[13,14]}$ This is especially true in biological sensing systems in which many sensing systems are made from aggregated proteins that show no or much reduced effect as monomers. ${ }^{[15]}$

Polythiophenes and polythienylethynylenes form an important group of $\pi$-conjugated polymers for sensing since there is a strong interplay between the chain conformation of polythiophenes and their properties. ${ }^{[16-18]}$ Generally, since only the backbone is conjugated, the visible optical absorption can be seen as a probe of the backbone conformation. A well-extended backbone conformation results in a red shift in absorption spectra, whereas a disordered backbone conformation results in a blue shift. ${ }^{[19,20]}$ While alkyl polythiophenes ${ }^{[21-24]}$ have been widely studied, less attention has been paid to derivatives bearing electron donating substituents, such as alkoxy- or alkylthio groups. Electron donating substituted polythiophenes and polythienylethynylenes present several advantages over alkyl functionalised ones. There 
is a substantial reduction of the band gap and the conducting state in the polymer is stabilised. In addition, the side chains can act as molecular recognition units for chemical sensing. ${ }^{[25]}$ Relatively fewer 3,4-alkylthiosubstituted polythiophenes have been studied. The interesting property that sets them apart is the ability of the sulphur atoms of thioether groups to act as complexing agents towards different 'soft' metallic ions. This introduces the possibility of using the sensitivity of the optoelectronic properties of the polythiophenes and polythienylethynylenes to the presence of species that may alter these properties to develop sensor systems. The compounds may therefore be used as the sensitive part of chemosensors $^{[26]}$ or as the catalyst for hydroformylation. ${ }^{[27]}$ Bis-thio-substituted aromatic compounds have previously been shown to be capable of coordinating to transition metals ${ }^{[28,29]}$ and alkylthio-substituted thiophenes have been shown to coordinate to transition metals. $^{[30,31]}$ In the present study, a series of chiral thioand oxo-substituted polythiophenes and polythienylethynylenes has been synthesised to investigate the influence of aggregation on the quenching of fluorescence upon coordination to palladium and ruthenium.

\section{Experimental Part}

See the Supporting Information.

\section{Characterisation of the Polymers and Complex 16}

Poly\{3,4-bis[3(S),7-dimethyloctyloxy]\}

thienylethynylene (12)

${ }^{1} \mathrm{H} \mathrm{NMR}\left(\mathrm{CDCl}_{3}, 400 \mathrm{MHz}\right) \delta=0.85(12 \mathrm{H}, \mathrm{d}, J=7.0 \mathrm{~Hz}), 0.94(6 \mathrm{H}, \mathrm{d}$, $J=6.2 \mathrm{~Hz}), 1.10-1.60(16 \mathrm{H}, \mathrm{m}), 1.62-1.72(2 \mathrm{H}, \mathrm{m}), 1.72-1.86(2 \mathrm{H}, \mathrm{m})$, 4.30-4.44 (4H, m).

${ }^{13} \mathrm{C}$ NMR $\left(\mathrm{CDCl}_{3}, 100 \mathrm{MHz}\right) \delta=19.6,22.7,24.7,28.0,29.6,36.9$, 37.4, 39.2, 71.2, 87.9, 83.9, 103.5, 150.1 .

GPC: $\bar{M}_{\mathrm{n}}=13370 \mathrm{~g} \cdot \mathrm{mol}^{-1}, \bar{M}_{\mathrm{W}}=23440 \mathrm{~g} \cdot \mathrm{mol}^{-1}$.

Poly $\{3,4$-bis[3(S),7-dimethyloctylthio $]\}$

thienylethynylene (13)

${ }^{1} \mathrm{H} \mathrm{NMR}\left(\mathrm{CDCl}_{3}, 400 \mathrm{MHz}\right) \delta=0.70-0.97(18 \mathrm{H}, \mathrm{m}), 0.99-1.75(20 \mathrm{H}$, $\mathrm{m}), 2.77-3.24(4 \mathrm{H}, \mathrm{m})$.

${ }^{13} \mathrm{C} \mathrm{NMR}\left(\mathrm{CDCl}_{3}, 100 \mathrm{MHz}\right) \delta=19.41,22.64,24.68,27.97,30.31$, 32.07, 36.60, 36.96, 39.25, 76.68, 125.51, 135.76 .

GPC: $\bar{M}_{\mathrm{n}}=14800 \mathrm{~g} \cdot \mathrm{mol}^{-1}, \bar{M}_{\mathrm{W}}=39600 \mathrm{~g} \cdot \mathrm{mol}^{-1}$.

Poly $\{3,4$-bis $[3(S), 7$-dimethyloctylthio $]\}-\left[3^{\prime}, 4^{\prime}-\right.$

bis(3,7-dimethyloctyloxy)]-bis(thienylethynylene) (14)

${ }^{1} \mathrm{H} \mathrm{NMR}\left(\mathrm{CDCl}_{3}, 400 \mathrm{MHz}\right) \delta=0.60-0.98(36 \mathrm{H}, \mathrm{m}), 0.98-1.77(40 \mathrm{H}$, m), $2.94-3.13(4 \mathrm{H}, \mathrm{m}), 4.40-4.60(4 \mathrm{H}, \mathrm{m})$.
${ }^{13} \mathrm{C} \mathrm{NMR}\left(\mathrm{CDCl}_{3}, 100 \mathrm{MHz}\right) \delta=19.36,19.63,22.61,22.71,24.67$, 24.72, 27.97, 29.66, 30.38, 32.08, 36.82, 36.93, 37.39, 39.16, 39.24, 39.27, 71.40, 76.67, 103.52, 125.54, 135.72, 150.02 .

GPC: $\bar{M}_{\mathrm{n}}=15470 \mathrm{~g} \cdot \mathrm{mol}^{-1}, \bar{M}_{\mathrm{w}}=33700 \mathrm{~g} \cdot \mathrm{mol}^{-1}$.

Poly\{3,4-bis[3(S),7-dimethyloctylthio]\}thiophene (15)

${ }^{1} \mathrm{H}$ NMR $\left(\mathrm{CDCl}_{3}, 400 \mathrm{MHz}\right) \delta=0.78-0.95(18 \mathrm{H}, \mathrm{m}), 1.02-1.68(20 \mathrm{H}$, m), 2.82-2.96 (4H, m).

${ }^{13} \mathrm{C} \mathrm{NMR}\left(\mathrm{CDCl}_{3}, 100 \mathrm{MHz}\right) \delta=19.39,22.62,24.71,27.95,29.41$, $32.36,34.78,37.03,39.30,143.15,145.42$.

GPC: $\bar{M}_{\mathrm{n}}=11180 \mathrm{~g} \cdot \mathrm{mol}^{-1}, \bar{M}_{\mathrm{w}}=13570 \mathrm{~g} \cdot \mathrm{mol}^{-1}$.

3,4-Bis(3(S),7-dimethyloctylthio)thiophene-

bis(2,2'-bipyridyl)-ruthenium(II) di(tetrafluoroborate) (16)

${ }^{1} \mathrm{H}$ NMR $\left(\mathrm{CDCl}_{3}, 400 \mathrm{MHz}\right) \delta=0.62-0.90(18 \mathrm{H}, \mathrm{m}), 0.90-1.18(8 \mathrm{H}$, $\mathrm{m})$ 1.18-1.37 (4H, m), $1.38-1.50(4 \mathrm{H}, \mathrm{m}), 1.53-1.82(4 \mathrm{H}, \mathrm{m})$, 2.12-2.22 (4H, m), 7.42-7.54 (2H, m), 7.66-7.74 (4H, m), 7.82-7.88 $(2 \mathrm{H}, \mathrm{m}), 7.94-8.06(2 \mathrm{H}, \mathrm{m}), 8.22-8.37(2 \mathrm{H}, \mathrm{m}), 8.41-8.56(2 \mathrm{H}, \mathrm{m})$, 8.58-8.63 (2H, m), 9.03-9.14 (2H, m).

Crystal data: $[\mathrm{C} 44 \mathrm{H} 60 \mathrm{~N} 4 \mathrm{RuS} 3]^{2+} \cdot 2 \mathrm{BF}_{4}^{-}, M=1015.86$, orange, needle-shaped crystal $\left(0.03 \times 0.09 \times 0.33 \mathrm{~mm}^{3}\right)$, monoclinic, space group P21 (no. 4) with $a=13.719(2), b=12.0218(10), c=15.802(2)$ $\AA$, $\beta=110.727(12), V=2437.5(5) \AA^{3}, Z=2, D_{\mathrm{c}}=1.384 \mathrm{~g} \cdot \mathrm{cm}^{-3}$, $\mu($ Mo $\mathrm{K} \alpha)=0.516 \mathrm{~mm}^{-1}, T=150 \mathrm{~K}, 61776$ reflections measured, 11199 independent, $R_{\text {int }}=0.0534, R_{\sigma}=0.0482$. Atoms C404-C498 of one of the aliphatic side chains are disordered and described with a two-site disorder model. Restraints were necessary to maintain a reasonable geometry. Refinement of 549 parameters converged at a final wR2 value of 0.1405 (all data), $R 1=0.0521$ [for 9196 reflections with $I>2 \sigma(\mathrm{I})], S=1.024,-0.57<\Delta \rho<1.45 \mathrm{e} \cdot \AA^{-3}$. The Flack $x$-parameter is $-0.02(3)$, confirming the absolute configuration of the starting material. Crystallographic data for the structural analysis have been deposited with the Cambridge Crystallographic Data Centre (reference number CCDC 012668). Copies of this information may be obtained free of charge from The Director, CCDC, 12 Union Road, Cambridge CB2 1EZ, UK (Fax: 44-1223-336-033; E-mail: deposit@ccdc.cam.ac.uk; or World Wide Web: http://www.ccdc.cam.ac.uk).

\section{Results and Discussion}

\section{Synthesis of Polymers (12-15)}

To investigate the properties of alkylthio-substituted polythiophenes and polythienylethynylenes 12-15 (Scheme 1), monomers with solubilising 3,7-dimethyloctyl alkyl chains were synthesised (Scheme 1). 3,4-Bis(3,7- dimethyloctylthio)thiophene, 5, was then either polymerised directly, by oxidative coupling with iron(III) chloride, to give polythiophene $\mathbf{1 5}$, or further modified to give the monomers necessary for polymerisation to polythienylethynylenes 12-14. This was achieved by iodination at the 2- and 5-position by $N$-iodosuccinimide (NIS). Some of the iodinated product, 7, was set aside for later reaction, while the rest was acetylated by reaction with trimethylsilylacetylene (TMSA) catalysed by tetrakis(triphenylphosphine)palladium(0) 


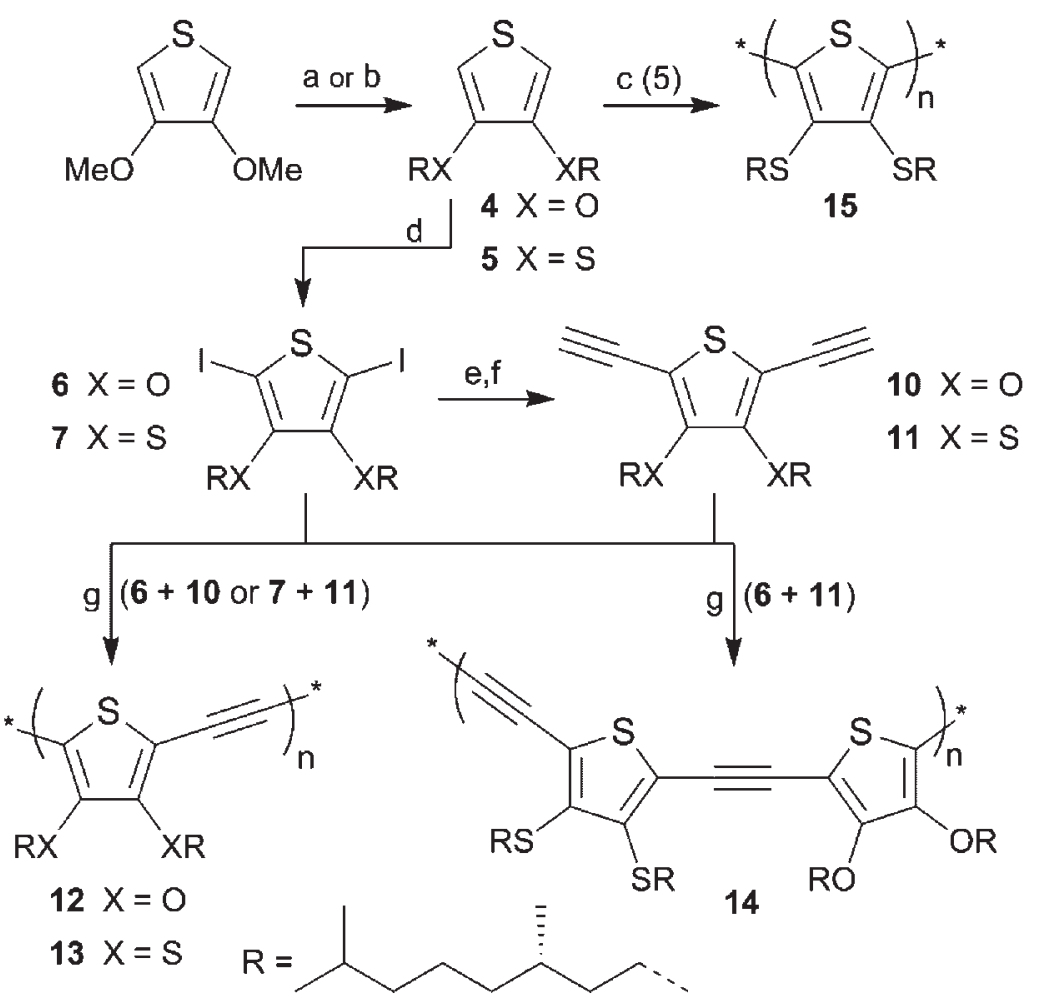

a) $\mathrm{ROH}$ as solvent, $90{ }^{\circ} \mathrm{C} 3$ days; b) $\mathrm{RSH}$ as solvent, $100^{\circ} \mathrm{C} 14$ days.

c) $\mathrm{FeCl}_{3}, \mathrm{CHCl}_{3}, \mathrm{RT} 16 \mathrm{~h}$; d) NIS, DMF, RT $48 \mathrm{~h}$; e) TMS-acetylene, $\mathrm{Pd}\left(\mathrm{PPh}_{3}\right)_{4}$, Cul, RT $16 \mathrm{~h}$; f) TBAF, RT $\left.15 \mathrm{~min} ; \mathrm{g}\right) \mathrm{Pd}\left(\mathrm{PPh}_{3}\right)_{4}, \mathrm{Cul}, 60^{\circ} \mathrm{C} 16 \mathrm{~h}$.

Scheme 1. Synthesis of polymers 12-15.

and copper(I) iodide. The TMS-protected intermediate $\mathbf{9}$ is an air- and moisture-stable liquid. Treatment of $\mathbf{9}$ with tetrabutylammonium fluoride removes the protecting group to give the free diacetylene $\mathbf{1 1}$, which is a clear colourless liquid that darkens upon prolonged standing. A similar procedure was used to convert the oxo-version, $\mathbf{4}$, into its iodo-substituted, $\mathbf{6}$, and acetylene substituted, 10, analogues. These monomers were then polymerised via Pd-catalysed polycondensation to give the corresponding polymers 12-14.>. ${ }^{[1,32,33]}$ The molecular weights of the polymers were determined by gel permeation chromatography in chloroform against polystyrene standards; the weight-average molecular weight, $\bar{M}_{\mathrm{w}}$, and the numberaverage molecular weight, $\bar{M}_{\mathrm{n}}$, range between $13600-$ 39600 and $11200-15500 \mathrm{~g} \cdot \mathrm{mol}^{-1}$, respectively (see the Experimental Part and the Supporting Information), giving polydispersity indexes $\bar{M}_{\mathrm{w}} / \bar{M}_{\mathrm{n}}$ of $1.2-2.7$.

\section{Aggregation}

The aggregation behaviour of polymers $\mathbf{1 2 - 1 5}$ was investigated in solution and in the solid state. As would be expected, in chloroform none of the chiral polymers 12-15 exhibit any circular dichroism signal as they all adopt a random coil conformation. The absorption spectra of $\mathbf{1 2}$ in dilute chloroform solution display an absorption maximum at $441 \mathrm{~nm}$ (Figure 1 and 2) while the absorption spectra of the thio-substituted polymers are similar to those of 12, but are broadened and the peak is red-shifted by as much as $30 \mathrm{~nm}$ (Figure 2). When dissolved in $n$-butanol and in the solid state as a thin film on glass, spin coated from a chloroform solution, the oxosubstituted polythienylethynylene $\mathbf{1 2}$ exhibits a pronounced circular dichroism signal showing a bisignated Cotton effect at the position of the $\pi-\pi^{*}$ band, indicating a preferred chirality in the aggregated species formed (Figure 1). This phenomenon has already been observed for other conjugated polymers and explained by the aggregation of polymer chains. ${ }^{[34-36]}$ Similar Cotton effects were observed when other alcohols were used as the solvent. In contrast to this, no circular dichroism signal is observed for any of the polymers, 13-15, containing thiosubstituted thiophene units in either $n$-butanol or in the solid state. This may be an indication that the presence of a thiosubstituent prevents the formation of chiral aggregates in which the side chains are able to interact with each other and direct chiral assembly. Instead, the aggregates form without chiral preference. The absorption spectra of $\mathbf{1 2}$ in a

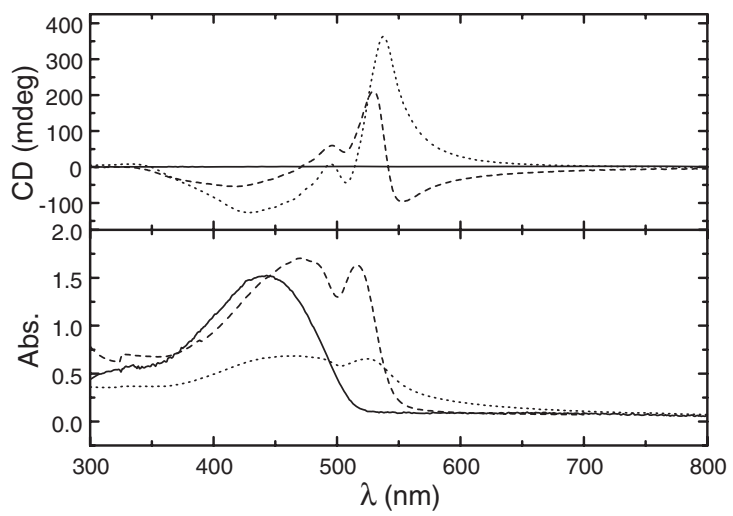

Figure 1. UV-vis and circular dichroism spectra of polythienylethynylene 12, in chloroform (solid line), in $n$-butanol (dotted line) and in the solid state as a thin film (dashed line). 

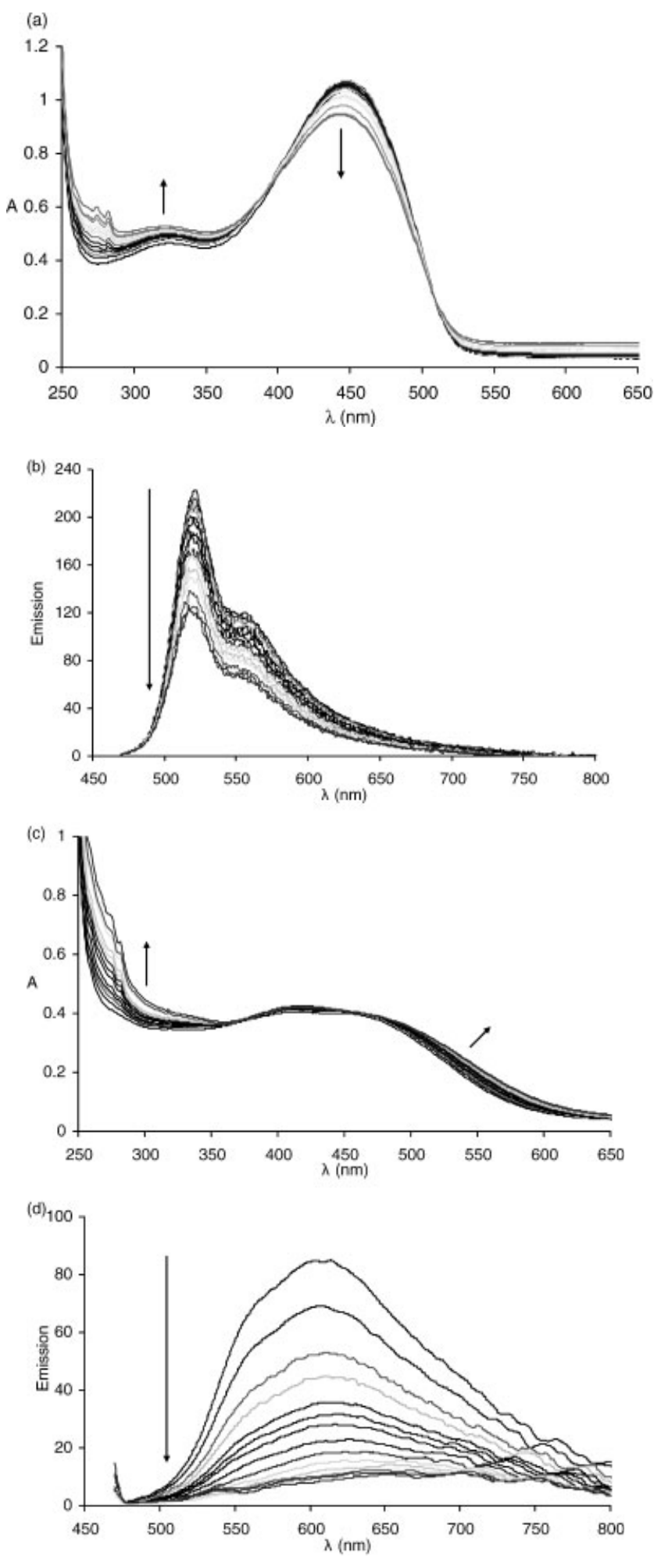
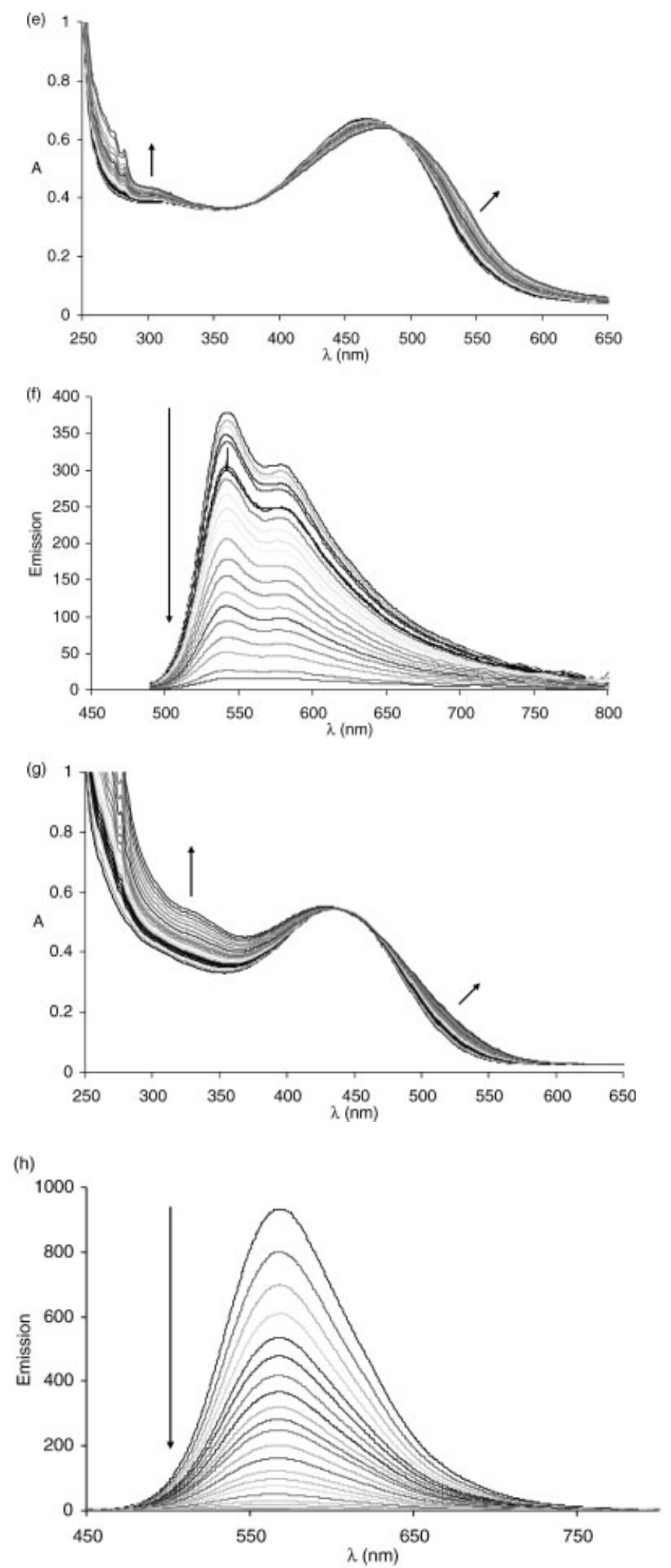

Figure 2. UV-vis and fluorescence spectra of polythienylethynylenes $\mathbf{1 2}$ ( $\mathrm{a}$ and b), $\mathbf{1 3}$ (c and d) and $\mathbf{1 4}$ (e and f) and polythiophene $\mathbf{1 5}$ (g and $\mathrm{h}$ ) in chloroform with bis(benzonitrile)palladium(II) chloride. Arrows indicated the changes upon adding bis(benzonitrile)palladium(II) chloride. 
spin-coated film (from chloroform) display an absorption maximum at $470 \mathrm{~nm}$. The spectra of the $n$-butanol solution and of the film also show secondary peaks at 516 and $525 \mathrm{~nm}$, respectively (Figure 1). While the thiosubstituted polymers, 13-15, show evidence of aggregation through the nonlinear dependence on concentration of the absorption spectra of their solutions in $n$-butanol, they lack the distinctive secondary absorption peak at higher wavelengths observed in the case of polythienylethynylene $\mathbf{1 2 .}{ }^{[37]}$ Similar results are obtained when dissolving the polymer in apolar solvents such as hexane, heptane and dodecane. ${ }^{[38,39]}$

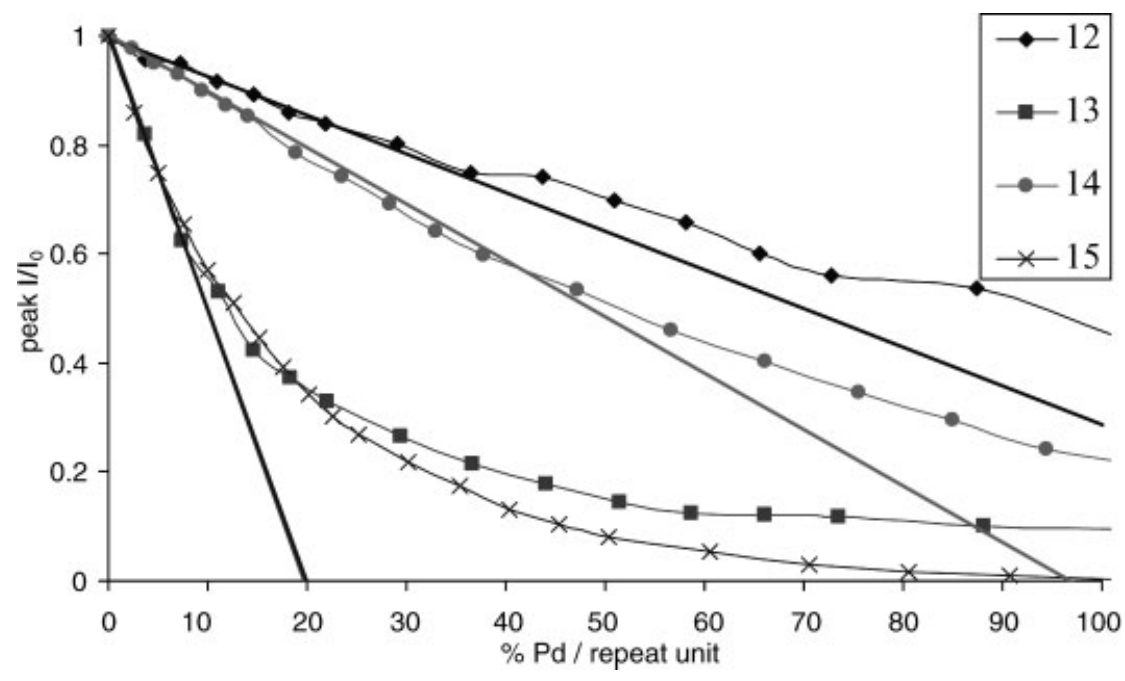

Figure 3. The fluorescence decrease in polythiophenes and polythienylethynylenes 12-15 with respect to the proportion of palladium added.

\section{Metal Coordination and Sensing}

Having seen from previous work ${ }^{[31]}$ that complexation of transition metals was possible, the effect of coordination on the optical properties of 12-15 were studied. The thio-substituted polymers $\mathbf{1 3}$ and $\mathbf{1 5}$ were titrated in chloroform with bis(benzonitrile)palladium(II) chloride, while their UV-vis and fluorescence spectra were monitored. There was minimal change in UV-vis absorption spectrum due to the coordination of the palladium to the polymers, though a slight broadening could be seen (Figure 2). The increase below $350 \mathrm{~nm}$ is due to the absorption of the palladium species itself. In contrast, the effect of the titration with bis(benzonitrile)palladium(II) chloride on the fluorescence of polythiophene $\mathbf{1 5}$ is marked. The emission is quenched almost completely by the addition of one equivalent of palladium per repeat unit. The initial rate of quenching projects to a quenching of five repeat units per palladium, giving an indication of the degree of conjugation in the polymer in solution (Figure 3). A similar situation exists for the quenching of polythienylethynylene $\mathbf{1 3}$ by the palladium. While the absolute intensity of the fluorescence of polythienylethynylene $\mathbf{1 3}$ is significantly less than that of polythiophene 15 (Figure 2) the initial rate of quenching is the same, at five repeat units per palladium, with the initial rate projection being almost superimposed upon that of polymer $\mathbf{1 5}$ in Figure 3. The residual fluorescence with one equivalent of palladium present in the solution of polythienylethynylene $\mathbf{1 3}$ may be an indication of a lower binding strength than that of polythiophene 15, thus necessitating a higher concentration of palladium to achieve a complete quenching.

A comparison of coordination ability of the polythienylethynylene $\mathbf{1 3}$ and its oxo-equivalent $\mathbf{1 2}$ was also carried out. Since the oxygens of polythienylethynylene $\mathbf{1 2}$ do not act as ligands towards the palladium, an increase in the extent to which nonspecific binding and also coordination by the thiophene itself contributes to quenching. To further understand this process, alternating copolymer 14 was investigated in the same way. While the limited effect of the palladium titration of polythienylethynylenes $\mathbf{1 2}$ and $\mathbf{1 4}$ on the UV-vis spectra (Figure 2) is very similar to that obtained for the palladium titration of polythiophene 15 and polythienylethynylene $\mathbf{1 3}$, the effect of the titration on the fluorescence is markedly different. The limited effect of the titration of the palladium species on chloroform solutions of polythienylethynylenes $\mathbf{1 2}$ and 14 can be seen in Figure 3. Without the bis-thioethers there is only nonspecific binding and the possibility of coordination of the thiophene to the palladium to allow for quenching. As a result, the quenching is much reduced and the initial rate projects to the quenching of 0.7 repeat units per palladium, compared to five repeat units for the thio version of the polymer, 13. The effect of palladium addition to the alternating copolymer, polythienylethynylene 14, is to give quenching at a level much greater than the completely oxo-version, 12, but less than that of the completely thio-version, $\mathbf{1 3}$. The initial rate of quenching projects to a quenching of one repeat unit per palladium. Since each repeat unit has two thiophenes in it, the fluorescence from both these thiophenes is being quenched by one palladium.

A ruthenium complex of $\mathbf{5}$ has also been synthesised to show that these materials are capable of coordinating to metals other than palladium. ${ }^{[29,40]}$ The synthesis required the use of silver tetrafluoroborate to drive the reaction by the precipitation of silver chloride from the reaction 




Figure 4. Molecular structure of $\mathbf{1 6}$, determined by X-ray crystallography. The minor disorder component, counter ions and the hydrogen atoms are omitted for clarity. Selected bond distances $\left({ }^{\circ}\right)$ and angles $\left({ }^{\circ}\right)$ : Ru1---S301 $=2.3423(10)$, Ru1---S401=2.3535(13), S301---Ru1---S401 = 86.41(5).

mixture. Once this was done 16 , the bis-bipy ruthenium(II) complex of $\mathbf{5}$, was formed. A crystal structure was obtained to confirm that the two sulphur atoms were, indeed, coordinating directly to the ruthenium (Figure 4). It is interesting to note that no fluorescence could be observed for 16, although a wide range of different solvents were tried.

\section{Conclusion}

A series of chiral thio- and oxo-substituted polythiophenes and polythienylethynylenes has been synthesised and investigated for aggregation and quenching of fluorescence upon coordination to palladium. The replacement of an oxo-linkage with a thio-linkage distorts and/or inhibits the aggregation behaviour such that there is no longer a preferred chirality in the assemblies and in some cases no or much reduced aggregation. It has been established that these alkylthio-substituted polythiophenes and polythienylethynylenes do act as sensors for palladium, by quenching of their fluorescence to a significantly greater extent than the quenching observed for nonthio functionalised polythiophenes and polythienylethynylenes.

The slightly lower than expected affinity of these alkylthio-substituted polythiophenes and polythienylethynylenes for the palladium makes them less useful as practical sensors, but the work demonstrates proof of principle and establishes a basis for future research for the improvement of this system.
Acknowledgements: The authors would like to acknowledge STW for funding. This work was supported in part (A. L. S.) by the Council for Chemical Sciences of the Netherlands Organisation for Scientific Research (CW-NWO).

Received: May 31, 2007; Accepted: June 22, 2007; DOI: 10.1002/ marc.200700399

Keywords: chiral; conjugated polymers; metal polymers complexes; self-assembly; sensors

[1] T. A. Skotheim, R. L. Elsenbaumer, J. R. Reynolds, Eds., "Handbook of Conducting Polymers", Marcel Dekker, New York 1998.

[2] Special issue on conjugated polymers, Chem. Mater. 2004, 16, 4381.

[3] P. Leclere, M. Surin, P. Viville, R. Lazzaroni, A. F. M. Kilbinger, O. Henze, W. J. Feast, M. Cavallini, F. Biscarini, A. P. H. J. Schenning, E. W. Meijer, Chem. Mater. 2004, 16, 4452.

[4] D. T. McQuade, A. E. Pullen, T. M. Swager, Chem. Rev. 2000, 100, 2537.

[5] M. D. Disney, J. Zheng, T. M. Swager, P. H. Seeberger, J. Am. Chem. Soc. 2004, 126, 13343.

[6] C. H. Fan, K. W. Plaxco, A. J. Heeger, J. Am. Chem. Soc. 2002, 124, 5642.

[7] J. S. Yang, T. M. Swager, J. Am. Chem. Soc. 1998, 120, 11864.

[8] O. Zhou, T. M. Swager, J. Am. Chem. Soc. 1995, 117, 7017.

[9] P. Bäuerle, S. Scheib, Acta Polym. 1995, 46, 124.

[10] B. Wang, M. R. Wasielewski, J. Am. Chem. Soc. 1997, 119, 12.

[11] G. Rimmel, P. Bauerle, Synth. Met. 1999, 102, 1323.

[12] R. Purrello, S. Gurrieri, R. Lauceri, Coord. Chem. Rev. 1999, 192, 683. 
[13] M. Gaidi, J. L. Hazemann, I. Matko, B. Chenevier, M. Rumyantseva, A. Gaskov, M. Labeau, J. Electrochem. Soc. 2000, 147, 3131.

[14] M. H. Chung, Y. C. Chung, B. C. Chun, Colloids Surf. B 2003, 29 , 75 .

[15] M. K. Campbell, "Biochemistry", Saunders College Pub, Philadelphia 1999.

[16] E. E. Havinga, I. Rotte, E. W. Meijer, W. Tenhoeve, H. Wynberg, Synth. Met. 1991, 41, 473.

[17] S. A. Chen, J. M. Ni, Macromolecules 1992, 25, 6081.

[18] A. O. Patil, A. J. Heeger, F. Wudl, Chem. Rev. 1988, 88, 183.

[19] S. Hotta, S. D. D. V. Rughooputh, A. J. Heeger, F. Wudl, Macromolecules 1987, 20, 212.

[20] K. C. Lim, A. J. Heeger, J. Chem. Phys. 1985, 82, 522.

[21] T.-A. Chen, X. M. Wu, R. D. Rieke, J. Am. Chem. Soc. 1995, 117 233.

[22] M. D. McClain, D. A. Whittington, D. J. Mitchell, M. D. Curtis, J. Am. Chem. Soc. 1995, 117, 3887.

[23] R. D. McCullough, S. P. Williams, S. Tristram-Nagle, M. Jayaraman, P. C. Ewbank, L. Miller, Synth. Met. 1995, 69, 279.

[24] Y. Miyazaki, T. Yamamoto, Synth. Met. 1994, 64, 69.

[25] P. Bäuerle, G. Götz, A. Synomczyk, J. Heinze, Liebigs Ann. 1996, 279.

[26] T. M. Swager, Acc. Chem. Res. 1998, 31, 201.

[27] S. Gladiali, D. Fabbri, L. Kollar, C. Claver, N. Ruiz, A. Alvarez-Larena, J. F. Piniella, Eur. J. Inorg. Chem. 1998, 113.
[28] Z. A. Bayir, Dyes Pigm. 2005, 65, 235.

[29] R. Prasad, A. Kumar, Inorg. Chim. Acta 2005, 358, 3201.

[30] L. Antolini, G. Minghetti, A. Mucci, F. Parenti, L. Pigani, G. Sanna, R. Seeber, C. Zanardi, Inorg. Chim. Acta 2005, 358, 3033.

[31] F. Goldoni, L. Antolini, G. Pourtois, A. P. H. J. Schenning R. A. J. Janssen, R. Lazzaroni, J. L. Brédas, E. W. Meijer, Eur. J. Inorg. Chem. 2001, 821.

[32] B. M. W. Langeveld-Voss, R. A. J. Janssen, E. W. Meijer, J. Mol. Struct. 2000, 521, 285.

[33] D. Fichou, Ed., "Handbook of Oligo- and Polythiophenes", Wiley-VCH, Weinheim, New York 1999.

[34] F. Goldoni, R. A. J. Janssen, E. W. Meijer, Polym. Prepr. (Am. Chem. Soc., Div. Polym. Chem.) 1998, 39, 1049.

[35] F. Goldoni, R. A. J. Janssen, E. W. Meijer, J. Polym. Sci., Part A: Polym. Chem. 1999, 37, 4629.

[36] B. M. W. Langeveld-Voss, R. A. J. Janssen, M. P. T. Christiaans, S. C. J. Meskers, H. Dekkers, E. W. Meijer, J. Am. Chem. Soc. 1996, 118, 4908.

[37] J. R. Matthews, F. Goldoni, A. P. H. J. Schenning, E. W. Meijer, Chem. Commun. 2005, 5503.

[38] D. Fichou, Ed., "Handbook of Oligo- and Polythiophenes", Wiley-VCH, Weinheim, New York 1999, p. 26.

[39] D. A. Dos Santos, J. L. Brédas, Synth. Met. 1994, 67, 315.

[40] R. Prasad, E. Murguly, N. R. Branda, Chem. Commun. 2003, 1462. 